\title{
Avaliação do nível de percepção dos riscos de infecção pelo SARS-CoV-2 e da acessibilidade a informações sobre a Covid-19 no Brasil
}

\author{
Assessment of the level of perception of the risks of SARS-CoV-2 infection \\ and of the accessibility to information about Covid-19 in Brazil
}

\section{Evaluación del nivel de percepción de los riesgos de infección por SARS- CoV-2 y de la accesibilidad a informaciones sobre la Covid-19 en Brasil}

\author{
Murilo Noli da Fonseca ${ }^{1, a}$ \\ murilonoli@gmail.com | https://orcid.org/0000-0002-0718-3087
}

Larissa Maria da Silva Ferentz ${ }^{1, b}$

ferentzengenharia@gmail.com | https://orcid.org/0000-0001-5804-0361

Alexandre de Fátima Cobre ${ }^{2, c}$

alexandrecobre@gmail.com | https://orcid.org/00o0-0001-6642-3928

Danilo Raul Ossufo Momade ${ }^{2, d}$

danilomomadeo6@gmail.com | https://orcid.org/0000-0003-3899-2300

Carlos Mello Garcias ${ }^{1, e}$

carlos.garcias@pucpr.br | https://orcid.org/0000-0001-7982-5803

\footnotetext{
${ }^{1}$ Pontifícia Universidade Católica do Paraná, Programa de Pós-Graduação em Gestão Urbana. Curitiba, PR, Brasil.

2 Universidade Federal do Paraná, Programa de Pós-Graduação em Ciências Farmacêuticas. Curitiba, PR, Brasil.

a Especialização em Gestão Ambiental pela Faculdade Souza.

• Mestrado em Gestão Urbana pela Pontifícia Universidade Católica do Paraná.

c Mestrado em Ciências Farmacêuticas pela Universidade Federal do Paraná.

d Graduação em Ciências Farmacêuticas pela Universidade Federal do Paraná.

e Doutorado em Engenharia Civil pela Universidade de São Paulo.
}

\section{RESUMO}

A Covid-19 tem se revelado um problema emergencial de importância mundial. O estudo apresentado neste artigo tem como objetivo discutir a percepção e comunicação da população brasileira sobre os riscos de contrair a doença. Foi conduzido um estudo transversal envolvendo indivíduos adultos maiores de 18 anos residentes em todo o território brasileiro que responderam a um questionário eletrônico (adaptado de Betsch), entre os dias 4 e 15 de maio de 2020, sobre percepção e comunicação dos riscos de infecção pelo coronavírus. No estudo, foram incluídos 1.291 participantes, sendo em sua maioria servidores públicos $(56,2 \%, \mathrm{n}=725)$. Também constituíram maioria os pertencentes ao sexo feminino $(62,9 \%, \mathrm{n}=812)$ e os que têm nível superior ( $91,5 \%, \mathrm{n}=1181)$. Já os que residem no estado do Paraná, apesar de representarem menos da metade dos entrevistados $(35,9 \%, n=464)$, predominaram se comparados aos que habitam nas demais unidades federativas. Grande parte dos participantes tomou conhecimento da pandemia e obteve informações sobre ela a partir de diferentes fontes: entre elas, especialmente televisão (18,9\%), sites ou portais de notícias $(16,6 \%)$, mídias sociais $(16,5 \%)$, jornais impressos $(11,2 \%)$, profissionais de saúde $(8,9 \%)$, familiares e amigos (8\%) e mecanismos de pesquisa na internet $(6,3 \%)$. Em relação ao grau de 
confiabilidade das fontes de informação, a maioria dos participantes afirmou que tem alta confiança em informações provenientes dos profissionais de saúde $(76,1 \%, \mathrm{n}=982)$ e muitos expressaram baixa confiança em informações provenientes de folhetos $(35,3 \%, n=456)$, familiares e amigos $(46,7 \%, n=551)$, mídias sociais $(39,7 \%, \mathrm{n}=513)$ e telefonemas $(45,1 \%, \mathrm{n}=582)$. Com este estudo conclui-se que o nível de percepção e comunicação sobre a Covid-19 entre os que dele participaram é bom. No entanto, futuros estudos com abordagem quali-quantitativa são necessários para melhor aprofundamento do tema.

Palavras-chave: Covid-19; Gestão de riscos; Comunicação; Meios de comunicação; Infecção por coronavírus.

\section{ABSTRACT}

The Covid-19 has been revealing a public health emergency of global importance. The study presented in this article aims to discuss the perception and communication by the Brazilian population of the risks of contracting that disease. A cross-sectional study involving adults who was at least 18 years old living in Brazilian territory was developed asking them to answer from 4 to 15 May 2020 an electronic questionnaire (adapted from Betsch) about perception and communication of the risks of coronavirus infections. A total of 1,291 participants were included in the study and the most of them were civil servants $(56.2 \%, \mathrm{n}=725)$. Female $(62.9 \%, n=812)$ and people with higher education $(91.5 \%, \mathrm{n}=1181)$ also comprised more than $50 \%$ of the group. Although less than $50 \%$ of the total of participants $(35.9 \%, n=464)$ were residents of the state of Paraná, they predominated when compared to the people who live in the other states. Most participants were aware of the pandemic and get news about it from different sources of information: especially television (18.9\%), websites or portals of news (16.6\%), social media (16.5\%), newspapers (11.2\%), health workforce (8.9\%), family and friends (8\%) and search engines (6.3\%). Regarding the degree of confidence in the sources of information, the most of participants stated that they have high confidence in information given by health workforce $(76.1 \%, \mathrm{n}=982)$ and a great number of them expressed low confidence in information given by leaflets $(35.3 \%, \mathrm{n}=456)$, family and friends $(46.7 \%, \mathrm{n}=551)$, social media $(39.7 \%, \mathrm{n}=513)$ and phone $(45.1 \%, n=582)$. From this study we could conclude that the level of perception and communication about Covid-19 among their participants is good. However, future studies with a qualitative and quantitative approach are necessary to achieve a profounder understanding of the matter.

Keywords: Covid-19; Risk management; Communication; Mass media; Coronavirus infections.

\section{RESUMEN}

La Covid-19 se revela un problema de emergencia de salud pública de importancia mundial. Este artículo presenta un estudio que tiene como objetivo discutir la percepción y comunicación de la población brasileña acerca de los riesgos de contraer esa enfermedad. Ha sido realizado un estudio transversal con personas adultas mayores de 18 años residentes en todo el territorio brasileño que respondieron a un cuestionario electrónico (adaptado de Betsch), entre los días 4 y 15 de mayo, sobre percepción y comunicación de los riesgos de infección por el coronavirus. Se incluyeron en el estudio un total de 1.291 participantes, la mayoría de los cuales era de funcionarios públicos $(56,2 \%, \mathrm{n}=725)$. Mujeres también componían mayoría $(62,9 \%, \mathrm{n}=812)$ así como los que tenían estudios superiores $(91,5 \%, \mathrm{n}=1181)$. Por lo que toca a los residentes del estado de Paraná (35,9\%, $n=464)$, aunque no constituyan la mayor parte de los entrevistados, tienen un predominio si comparados con los que residen en el resto del país. Un gran número de participantes tuvieron noticia de la pandemia a través de diferentes fuentes de información: especialmente televisión $(18,9 \%)$, sitios web o portales de noticias $(16,6 \%)$, redes sociales $(16,5 \%)$, periódicos impresos $(11,2 \%)$, profesionales de la salud (8,9\%), familiares y amigos (8\%) y motores de búsqueda en internet $(6,3 \%)$. En cuanto al grado de confianza de las fuentes de información, la mayoría de los participantes manifestó tener alta confianza en la información de los profesionales de la salud $(76,1 \%, n=982)$ y muchos de ellos expresaron baja confianza en la información por medio de folletos $(35,3 \%, n=456)$, familiares y amigos $(46,7 \%, n=551)$, redes sociales $(39,7 \%, n=513)$ y teléfono $(45,1 \%, n=582)$. Ese estudio permite concluir que el nivel de percepción y comunicación sobre la Covid-19 entre los participantes es bueno. Sin embargo, son necesarios estudios futuros con un enfoque cualitativo y cuantitativo para comprender mejor el tema.

Palabras clave: Covid-19; Gestión de riesgos; Comunicación; Medios de comunicación; Infecciones por coronavirus. 
Contribuição dos autores:

Concepção e desenho do estudo: Murilo Noli da Fonseca.

Aquisição, análise ou interpretação dos dados: Murilo Noli da Fonseca, Alexandre de Fátima Cobre e Danilo Raul Ossufo Momade. Redação do manuscrito: Larissa Maria da Silva Ferentz.

Revisão crítica do conteúdo intelectual: Carlos Mello Garcias.

Declaração de conflito de interesses: não há.

Fontes de financiamento: o presente trabalho foi realizado com apoio da Coordenação de Aperfeiçoamento de Pessoal de Nível Superior - Brasil (CAPES) - Código de Financiamento 001.

\begin{abstract}
Considerações éticas: a pesquisa passou pelo Conselho Nacional de Ética de Pesquisa, tendo sido aprovado segundo o protocolo $n^{\circ} 3.993 .827$.
\end{abstract}

Agradecimentos/Contribuições adicionais: não há.

Histórico do artigo: submetido: 29 jul. 2020 | aceito: 01 fev. 2021 | publicado: 30 jun 2021.

Apresentação anterior: não houve.

Licença CC BY-NC atribuição não comercial. Com essa licença é permitido acessar, baixar (download), copiar, imprimir, compartilhar, reutilizar e distribuir os artigos, desde que para uso não comercial e com a citação da fonte, conferindo os devidos créditos de autoria e menção à Reciis. Nesses casos, nenhuma permissão é necessária por parte dos autores ou dos editores.

\title{
INTRODUÇÃO
}

Entre o final de 2019 e o início de 2020, um grupo de pacientes com doenças respiratórias agudas foi vinculado a um mercado atacadista de frutos do mar na cidade de Wuhan, província de Hubei, China. O patógeno foi identificado como um novo betacoronavírus de RNA envelopado (LU; ZHAO; LI et al., 2020), atualmente denominado coronavírus de síndrome respiratória aguda grave 2 (SARS-CoV-2), que possui similaridade filogenética ao SARS-CoV (ZHU; ZHANG; WANG et al., 2020). Desde então, inúmeras pessoas em diferentes países foram infectadas por ele e adquiriram a "Coronavirus Disease 2019" (Covid-19). Em 11 de março de 2020, a Organização Mundial da Saúde (OMS) declarou o surto de coronavírus de rápida disseminação e alta mobilidade e mortalidade (CHEN; ZHOU; DONG et al., 2020; HUANG; WANG; LI et al., 2020) como uma pandemia. Até o dia 14 de março daquele ano, 81.026 pessoas tinham sido infectadas na China e 62.205 em outros países, 5.388 tinham morrido (WHO, 2019). No Brasil, no mesmo ano, até o dia 11 de junho foram registrados 805.649 casos de infecção e 41.058 óbitos (BRASIL, 2020). Tal conjuntura criou desafios em diversos aspectos, sobretudo nos âmbitos econômico, político, social, saúde, entre outros.

Alguns desses desafios estão direta ou indiretamente relacionados à disponibilização e comunicação de informações sobre o risco de contágio da Covid-19. Isso ocorre porque as pessoas recebem uma enxurrada constante de informações, especialmente em virtude da existência de canais de notícia 24 horas e das mídias sociais. Essa sobrecarga levou a própria OMS a caracterizar o cenário de informações da Covid-19 como uma "abundância excessiva de informações", declarando a existência de "infodemia maciça" (WHO, 2019). Porém, informações erradas ou falsas são facilmente divulgadas (FRENKEL; ALBA; ZHONG, 2020), contribuindo para o aumento do medo e da indignação na população. Rumores e desinformação podem minar qualquer ação de saúde pública e devem ser desmascarados rapidamente (SCHMID; BETSCH, 2019).

Para aliviar essa situação, as autoridades de saúde pública precisam fornecer informações que sejam precisas, adaptadas às necessidades específicas de diferentes grupos populacionais, especialmente as 
dos mais vulneráveis (GLIK, 2007), facilmente compreensíveis e por meio de canais acessíveis em que o público confie e, por isso, os utilize. O fornecimento de informações com essas características possibilita que as percepções sejam atualizadas com base em mudanças na epidemiologia e faça com que o público adote escolhas bem informadas, tome medidas para se proteger melhor contra os riscos à saúde e cumpra as recomendações dos órgãos de saúde pública. Em outras palavras, se as pessoas tiverem informações precisas sobre os riscos enfrentados e o conhecimento da prevenção, existe a possibilidade de se ter um desempenho exitoso e de aumentar a conformidade com as recomendações de segurança pública indicadas pelas agências governamentais (BARRY, 2009).

Como as estratégias de comunicação são relevantes para a preparação e podem influenciar nesse comportamento, o presente artigo tem como objetivo principal avaliar a dinâmica da percepção da população em relação às informações disponibilizadas sobre a Covid-19 no Brasil. Ao explorar essas questões, que influenciam na percepção de risco, é possível otimizar estratégias de comunicação para garantir níveis apropriados de conscientização e o desenvolvimento de ações de prevenção, mitigação e preparação, tendo em vista sua influência na vulnerabilidade e na adaptação. Pois, "pode não haver maneira de prevenir uma pandemia de Covid-19 neste tempo globalizado, mas as informações verificadas são a prevenção mais eficaz contra a doença de pânico" (THE LANCET, 2020, tradução nossa).

\section{PERCEPÇÃO E COMUNICAÇÃO DE RISCO}

A comunicação é um dos principais elementos da gestão de risco de desastres, sobretudo os de natureza biológica, interligando e facilitando fluxos de informações e diálogos entre os outros elementos de sua estrutura. Ela é vista como um instrumento necessário desde a identificação e avaliação da situação de risco até a implementação e monitoramento de medidas. Ou seja, sem comunicação, a compreensão e a adoção de estratégias preventivas não podem ser praticadas. Além de ser uma ferramenta de gestão de risco, a comunicação faz parte do direito das pessoas de serem informadas dos riscos. A Convenção de Aarhus de 1981 estabelece os direitos dos cidadãos à informação, a serem ouvidos e a terem seus interesses considerados.

Para tornar o processo de comunicação eficaz, diversos modelos recomendam a necessidade de compreender a percepção de risco e as fontes de informação confiáveis (REYNOLDS; SEEGER, 2005). Para comunicar um risco, ele deve primeiro ser percebido. Ou seja, no início do processo de comunicação, pelo menos o comunicador deve estar ciente do risco e de sua relevância, caso contrário, não veria necessidade de comunicá-lo. Em seguida, os destinatários também devem perceber o risco comunicado como tal e interpretá-lo como algo que lhes diz respeito. Logo, a percepção tem influência no êxito da comunicação de risco, já que pode levar a diversos problemas se ignorada, mas também é esperado que esse processo modele a percepção (PING; WEHN; ZEVENBERGEN, 2016).

Geralmente, níveis mais altos de risco percebido aumentam a motivação de proteção, enquanto níveis mais baixos podem levar as pessoas a negligenciá-lo (NEUWIRTH; DUNWOODY; GRIFFIN, 2016). Por isso, desenvolver e apresentar uma informação é essencial para tornar a comunicação de risco eficaz. O modo como uma informação é apresentada, bem como sua origem e consistência, além da credibilidade atribuída à fonte e sua precisão influenciam direta e indiretamente a forma como as pessoas a interpretam e reagem a ela (MILETI; SORENSEN, 1990). Logo, a informação deve ser baseada em evidências e responder à desinformação assim como induzir um comportamento racional, adaptativo e protetor (RASMUSSEN; GOODMAN, 2018).

Pouco se sabe sobre a interação entre a mudança de epidemiologia, atenção da mídia, medidas de controle, percepção de risco e comportamento em saúde pública (REINTJES; DAS; KLEMM et al., 2016). Durante a pandemia de influenza A (H1N1) em 2009/2010, por exemplo, foi constatada uma assincronicidade entre as curvas da mídia e da epidemiologia. O tratamento que a mídia deu à H1N1 na Europa "diminuiu muito 
antes da epidemia atingir seu pico, e as percepções e comportamentos de risco público podem ter seguido a lógica da mídia, em vez da lógica epidemiológica” (REINTJES; DAS; KLEMM et al., 2016, tradução nossa). Pois o modo como as pessoas percebem o risco não está necessariamente atrelado ao risco real (PLIGT, 1996). Nesse caso, a incerteza da situação e a baixa percepção impediram a adoção de medidas de proteção recomendadas (WALTER; BOHMER; REITER, 2012).

\section{Ferramentas de comunicação de risco}

As ferramentas tradicionais incluem fontes impressas (jornais, revistas e folhetos); eletrônicas (televisão, rádio, telefone, filmes, documentários, internet); comunicações pessoais; aulas e atividades temáticas; visitas de estudo; eventos e ações públicas. Além dessas, as mídias sociais vêm crescendo como mecanismos de comunicação de informações sobre riscos (FELDMAN; CONTRERAS; KARLIN et al., 2016). Elas se referem a aplicativos baseados na internet que facilitam o compartilhamento de informações em computadores e dispositivos móveis, como as redes sociais (por exemplo, Facebook e Twitter), mensagens de texto, salas de bate-papo, fóruns de discussão e blogs. O uso de mídias sociais por agências governamentais tem crescido. Elas são vistas como um veículo efetivo do compartilhamento de informações para vários públicos, constituindo um canal de comunicação bidirecional entre cidadãos e governo (DZIALEK; BIERNACKI; KONIECZNY, 2019).

Até mesmo devido à existência de múltiplos canais de comunicação, as fontes escolhidas pelos cidadãos para receber informações confiáveis são diversas. Elas variam conforme as características demográficas e a comunidade local. Para garantir o efeito desejado, uma variedade de fontes, tradicionais e digitais, adaptadas a pessoas, grupos, comunidades e áreas específicas, considerando o contexto social e cultural local, deve ser utilizada para comunicar o risco. As pessoas, na maioria das vezes, confiam nas fontes de informação de risco consideradas concisas, acreditáveis, confiáveis, atenciosas, bem informadas, especializadas e honestas, cujas informações devem ser relevantes e capazes de prescrever alguma resposta (FELDMAN; CONTRERAS; KARLIN et al., 2016).

As fontes de informação mais utilizadas antes e durante um evento adverso são o rádio e a televisão (LAMOND; ADEKOLA; ADELEKAN et al., 2019). Isto sugere que as fontes de informação baseadas na web não são uma escolha universal para receber informações de risco. Por exemplo, um estudo envolvendo mais de 13 mil participantes durante a pandemia de H1N1 mostrou que a internet foi menos usada como fonte de informação do que a mídia tradicional, o que pode ter mudado desde então (WALTER; BOHMER; REITER, 2012). A idade é um dos elementos que prediz o uso ou a preferência por tipos de fontes de informação de risco (FELDMAN; CONTRERAS; KARLIN et al., 2016). Enquanto a internet e as mídias sociais são importantes fontes de informação sobretudo entre os mais jovens, os idosos tendem a utilizar canais tradicionais de comunicação como fontes de informação, dando preferência a jornais, revistas, folhetos, TV, rádio, telefone e boca-a-boca (FINSET; BOSWORTH; BUTOW et al., 2020). Eles também não desejam receber informações através de mídias sociais (BEAN; SUTTON; LIU et al., 2015).

\section{MATERIAIS E MÉTODOS}

A pesquisa aqui apresentada é um estudo observacional do tipo transversal envolvendo no mínimo mil participantes no Brasil. Os dados foram coletados por meio de um questionário eletrônico composto por cinco perguntas, adaptado do WHO Regional Office for Europe (2020), entre os dias 4 e 15 de maio de 2020. O questionário foi disponibilizado ao público através de mídias sociais (Facebook, WhatsApp, Instagram, entre outros). Foram considerados como critérios de inclusão: brasileiros adultos com idade igual ou superior a 18 anos residentes no país. Os dados coletados correspondem a: características sociodemográficas (idade, sexo, 
escolaridade, cidade/estado), fonte da informação sobre a Covid-19, confiança em relação às fontes de informação, fontes de informação usadas, confiança nas organizações de saúde e fonte de informação oficial de saúde.

As variáveis qualitativas (categóricas) são apresentadas na forma de frequência. As variáveis quantitativas foram estudadas de acordo com a distribuição normal pelo teste de Kolmogorov-Smirnov. Aquelas que tiveram distribuição normal são apresentadas na forma de média e desvio-padrão ao passo que aquelas sem esse tipo de distribuição são expressas mediante mediana e intervalo interquartil. O teste t-student, o teste One Way ANOVA, os modelos de regressão linear multivariada e regressão logística foram usados para a comparação das categorias e associações quando foi necessário. As análises estatísticas foram realizadas no software estatístico SPSS versão 20 (Chicago, USA). Valores de p<0,05 foram considerados significativos.

\section{RESULTADOS}

Ao todo, 1.291 pessoas participaram da pesquisa. A maior parte delas se concentra nas regiões Sul $(50,9 \%)$ e Sudeste $(26,1 \%)$, mesmo que a pesquisa tenha tido abrangência nacional.

\section{Características sociodemográficas}

A idade mediana dos participantes foi de 38 (IQR, 29-48) e a maioria dos indivíduos $(62,9 \%, \mathrm{n}=812$ ) eram do sexo feminino. Cerca de $91,5 \%(\mathrm{n}=1181)$ dos participantes possuem ensino superior, $8,4 \%(\mathrm{n}=108)$ ensino médio e $0,2 \%(n=2)$ ensino fundamental. Em relação à localização geográfica, a maioria dos participantes reside nos estados do Paraná $(35,9 \%, \mathrm{n}=464)$, de São Paulo (9,1\%, n=117) e de Santa Catarina ( $9,0 \%, n=116)$. A maior participação se deu por servidores públicos $(56,2 \%, n=725)$ e estudantes $18,1 \%$ $(n=234)$, cabendo destacar que, no período da pesquisa, cerca de $3,3 \%(n=42)$ dos entrevistados estavam desempregados (Tabela 1).

Tabela 1 - Características sociodemográficas dos participantes

\begin{tabular}{lcc}
\multicolumn{1}{c}{ Característica } & Frequência (n) & Percentagem (\%) \\
Sexo & 477 & \\
Masculino & 812 & 36,9 \\
Feminino & 2 & 62,9 \\
Not informed & & 0,2 \\
Nível de escolaridade & 2 & \\
Ensino Fundamental & 108 & 0,2 \\
Ensino Médio & 1181 & 8,4 \\
Ensino Superior & & 91,5 \\
Estado de residência & 81 & \\
Goiás & 72 & 6,3 \\
Minas Gerais & 464 & 5,6 \\
Paraná & 97 & 35,9 \\
Rio de Janeiro & 116 & 7,5 \\
Santa Catarina & 117 & 9,0 \\
São Paulo & 344 & 9,1 \\
Outros & & 26,6 \\
Ocupação & 26 & \\
Aposentado & 81 & 2,0 \\
Autônomo & 42 & 6,3 \\
Desempregado & 20 & 3,3 \\
Empresário & 234 & 1,5 \\
Estudante & 163 & 18,1 \\
Servidor privado & 725 & 12,6 \\
Servidor público & & 56,2 \\
\hline Fonte: elaborac̃o &
\end{tabular}

Fonte: elaboração dos autores. 
Durante o período da pesquisa, diversos estados adotaram medidas de flexibilização das restrições instituídas até então, sobretudo no que se refere à abertura do comércio. Mas, de 15 a 31 de maio daquele ano, houve no país um aumento de 57\% dos contaminados pela Covid-19 em comparação com o período anterior. Portanto, é necessário compreender como as pessoas têm lidado com as diferentes informações recebidas durante a pandemia, analisando o seu nível de confiança perante as fontes de informação mais utilizadas.

\section{Frequência de utilização das fontes de informação sobre a Covid-19}

No contexto de emergências e desastres em saúde pública, como a pandemia de Covid-19, as mídias desempenham um papel fundamental na conscientização do público acerca dos riscos. A sua utilização varia conforme as características dos indivíduos e das circunstâncias socioeconômicas. Quando indagados como souberam da pandemia do novo coronavírus, a maior parcela dos entrevistados teve conhecimento através de diferentes fontes de informação: especialmente por meio da televisão $(18,9 \%)$, sites ou páginas de notícias (16,6\%), mídias sociais (16,5\%), jornais impressos (11,2\%), profissionais de saúde $(8,9 \%)$, familiares e amigos (8\%) e mecanismo de pesquisa na internet (6,3\%). As menos utilizadas, por sua vez, foram rádio (5,2\%), e-mail (3,9\%), revistas $(1,5 \%)$, SMS (1,1\%), folhetos/panfletos $(0,7 \%)$, chamadas por telefone/celular (o,4\%) e cartas (o\%).

Imediatamente após o conhecimento sobre uma emergência em saúde pública, os indivíduos buscam informações em distintos tipos de fonte, desde a mídia impressa até as eletrônicas, especialmente televisão, rádio e mídias sociais (MASIP; ARAN-RAMSPOTT; RUIZ-CABALLERO et al., 2020). Atualmente, a transmissão rápida e clara de informações através de diferentes plataformas de mídia é essencial para alcançar um gerenciamento eficaz (PARK; BOATWRIGHT; JOHNSON-AVERY, 2019). Os entrevistados responderam que as seguintes fontes são frequentemente utilizadas: televisão, jornais, profissionais de saúde, sites ou páginas de notícias, mídias sociais (Facebook, Twitter e WhatsApp, por exemplo) e mecanismo de pesquisa do Google. As fontes de informação que nunca foram utilizadas pelos participantes para informação sobre Covid-19 foram: folhetos ou panfletos, cartas, revistas, e-mail e chamadas por celular ou telefone. A fonte de informação raramente utilizada foi o rádio (Tabela 2).

Tabela 2 - Dados sobre frequência de utilização das fontes de informação sobre a Covid-19

(continua)

\section{Característica $\quad$ Frequência (n) Porcentagem (\%)}

Com que frequência você usa as seguintes fontes de informação para se manter informado sobre o novo coronavírus?

[Televisão]

$\begin{array}{lcc}\text { Frequentemente } & 482 & 37,3 \\ \text { Nunca } & 156 & 12,1 \\ \text { Raramente } & 260 & 20,1 \\ \text { Sempre } & 393 & 30,4 \\ \text { [Rádio] } & & \\ \text { Frequentemente } & 230 & 17,8 \\ \text { Nunca } & 474 & 36,7 \\ \text { Raramente } & 478 & 37,0 \\ \text { Sempre } & 109 & 8,4 \\ \text { [Jornais] } & & \\ \text { Frequentemente } & 425 & 32,9\end{array}$


(continua)

\begin{tabular}{|c|c|c|}
\hline Característica & Frequência (n) & Porcentagem (\%) \\
\hline Nunca & 259 & 20,1 \\
\hline Raramente & 341 & 26,4 \\
\hline Sempre & 266 & 20,6 \\
\hline \multicolumn{3}{|l|}{ [Folhetos/Panfletos] } \\
\hline Frequentemente & 66 & 5,1 \\
\hline Nunca & 855 & 66,2 \\
\hline Raramente & 355 & 27,5 \\
\hline Sempre & 15 & 1,2 \\
\hline \multicolumn{3}{|l|}{ [Cartas] } \\
\hline Frequentemente & 19 & 1,5 \\
\hline Nunca & 1042 & 80,7 \\
\hline Raramente & 222 & 17,2 \\
\hline Sempre & 8 & 0,6 \\
\hline \multicolumn{3}{|l|}{ [Revistas] } \\
\hline Frequentemente & 135 & 10,5 \\
\hline Nunca & 697 & 54,0 \\
\hline Raramente & 412 & 31,9 \\
\hline Sempre & 47 & 3,6 \\
\hline \multicolumn{3}{|l|}{ [Familiares e amigos] } \\
\hline Frequentemente & 441 & 34,2 \\
\hline Nunca & 262 & 20,3 \\
\hline Raramente & 495 & 38,3 \\
\hline Sempre & 93 & 7,2 \\
\hline \multicolumn{3}{|l|}{ [Profissionais de saúde] } \\
\hline Frequentemente & 518 & 40,1 \\
\hline Nunca & 47 & 3,6 \\
\hline Raramente & 213 & 16,5 \\
\hline Sempre & 513 & 39,7 \\
\hline \multicolumn{3}{|l|}{ [Sites ou portais de notícias] } \\
\hline Frequentemente & 553 & 42,8 \\
\hline Nunca & 85 & 6,6 \\
\hline Raramente & 170 & 13,2 \\
\hline Sempre & 483 & 37,4 \\
\hline \multicolumn{3}{|c|}{ [Mídias sociais (Facebook, Twitter, WhatsApp)] } \\
\hline Frequentemente & 458 & 35,5 \\
\hline Nunca & 284 & 22,0 \\
\hline Raramente & 345 & 26,7 \\
\hline Sempre & 204 & 15,8 \\
\hline \multicolumn{3}{|c|}{ [Mecanismo de pesquisa (Google)] } \\
\hline Frequentemente & 489 & 37,9 \\
\hline Nunca & 187 & 14,5 \\
\hline Raramente & 277 & 21,5 \\
\hline Sempre & 338 & 26,2 \\
\hline \multicolumn{3}{|l|}{ [E-mail] } \\
\hline Frequentemente & 172 & 13,3 \\
\hline
\end{tabular}


(conclusão)

\begin{tabular}{lll}
\multicolumn{1}{c}{ Característica } & Frequência (n) & Porcentagem (\%) \\
\hline Nunca & 673 & 52,1 \\
Raramente & 400 & 31,0 \\
Sempre & 46 & 3,6 \\
[Chamada por telefone/celular] & & \\
Frequentemente & 63 & 4,9 \\
Nunca & 942 & 73,0 \\
Raramente & 264 & 20,4 \\
Sempre & 22 & 1,7 \\
\hline
\end{tabular}

Fonte: elaboração dos autores.

Entre as fontes apresentadas, os sites e os portais de notícias são as mais utilizadas pelos participantes na busca de informações sobre a Covid-19. Como existem várias opções de informação na internet, é mais fácil para os usuários identificar se existe alguma inconsistência entre as páginas oficiais. Há quatro anos, a internet não era considerada como fonte confiável para informação por cerca de $80 \%$ das pessoas (BRASIL, 2016). No entanto, com o passar dos anos, a população foi aprendendo a localizar as opções mais seguras, assim como a buscar mais de uma fonte, se necessário. Essa procura vai ao encontro das pesquisas sobre o novo coronavírus realizadas pelos participantes deste estudo, correspondendo a 64,1\% das respostas obtidas.

Embora o perfil televisivo tenha mudado, uma vez que as pessoas tendem a assistir a programas de TV ao mesmo tempo que utilizam a internet, essa situação tem fortalecido a televisão (PROULX; SHEPATIN, 2012). Ela ainda é a fonte dominante de informação e entretenimento no mundo (MURDOCH; TUMA; VERNOCCHI, 2013). O seu uso se deve principalmente porque as pessoas a percebem como mais credível do que as mídias sociais (AUSTEN; LIU; JIN, 2012) e por ser um meio ideal para compartilhar mensagens instrucionais durante crises (FRISBY; VEIL; SELLNOW, 2014). Nos Estados Unidos, por exemplo, a televisão é o meio mais usado em situações de emergência e crise (HEATH; O’HAIR, 2009). No Brasil, por sua vez, de acordo com os dados do Instituto Brasileiro de Geografia e Estatística (IBGE), em 2017, 96,7\% dos domicílios possuíam um aparelho de TV, enquanto, segundo o mesmo órgão, no mesmo ano apenas 74,9\% dos domicílios tinham acesso à internet (IBGE, 2018). A partir desse contexto, é possível compreender por que os participantes da pesquisa aqui apresentada apontaram a televisão como uma das fontes mais frequentes utilizadas para obterem informações sobre o novo coronavírus (67,7\%).

Segundo a pesquisa brasileira em mídia, 32\% dos brasileiros leem jornal, tendo preferência pela versão impressa. A utilização desse meio de comunicação está, em sua maioria, nas pessoas com faixa etária entre 45 e 65 anos ou mais (PARK; BOATWRIGHT; JOHNSON-AVERY, 2019). Na Espanha, os jornais online são a principal fonte de informação sobre o novo coronavírus (38,9\%), sendo seguidos pela televisão (33,9\%) e muito à frente dos serviços de mídia social e de mensagens $(11,4 \%)$ assim como de rádio $(8,3 \%)$ (MASIP; ARAN-RAMSPOTT; RUIZ-CABALLERO et al., 2020). Conforme exposto anteriormente, embora o jornal impresso não seja um dos meios mais utilizados de comunicação nos dias atuais, ele ainda expressa credibilidade para as pessoas, sobretudo aqueles em versão online, tornando-se uma fonte confiável de notícias. Com o aumento da busca de informações, a frequência de sua utilização pelos participantes deste estudo chegou a $53,5 \%$.

No mundo, Facebook, WhatsApp e Instagram estão entre as mídias sociais mais utilizadas. No Brasil, o uso dessas mídias teve um aumento de $58 \%$ durante a pandemia do novo coronavírus (KEMP, 2020). Na última semana de março de 2020, por exemplo, o uso de informações das mídias sociais cresceu $55 \%$ na 
Espanha, 30\% na Itália, 18\% no Reino Unido, 14\% na França e 11\% na Alemanha (GEVERS, 2020). Já, em abril de 2020, o uso do Facebook em seus serviços de mensagens aumentou mais de 50\% nas áreas mais afetadas pela Covid-19, e as chamadas de voz e vídeos dobraram no mesmo período em canais de mensagem e WhatsApp (MORGAN, 2020). Entretanto, apenas 51,3\% dos participantes da pesquisa apresentada aqui utilizam essas fontes para busca de informações sobre a pandemia. Esse fator está diretamente relacionado ao nível de confiança e às notícias falsas que são recebidas em grande volume pelos usuários, como já comentado anteriormente.

Considerando todos os meios apresentados, as notícias e informações oficiais dos profissionais de saúde tem adentrado por todas as fontes de comunicação atualmente. As pessoas não precisam necessariamente ir até uma unidade de saúde para solicitar informação. Além das mídias aqui expostas, existem também iniciativas de prefeituras municipais para o atendimento online, pelo telefone ou internet, por exemplo, sem que a população precise sair de casa. Baseado na frequência dessa busca pelo contato com profissionais de saúde, 79,8\% dos participantes deste estudo procuram notícias diretamente com esses profissionais. Embora as pessoas confiem nos profissionais de saúde, pôde ser observado que, com as medidas de flexibilização adotadas nos estados brasileiros no mês de maio de 2020, as pessoas começaram a frequentar o comércio, shoppings, bares, restaurantes e casas noturnas. Como resultado, o aumento de casos tem se elevado a cada dia.

Desse modo, infere-se que, algumas pessoas, mesmo que confiem nas orientações oficiais dos profissionais de saúde, ainda não acreditam que serão contaminadas pelo coronavírus e que, consequentemente, vão contrair a doença. Outro fator que pode ser a causa da falsa segurança das pessoas é a utilização da máscara, item indicado como obrigatório em todo o Brasil. Os especialistas afirmam que o uso de máscaras não impede que a contaminação ocorra, mas sim, minimiza as chances de uma contaminação em massa ocorrer. Ou seja, a medida mais efetiva encontrada até o momento continua sendo o isolamento social (MORI, 2020; OLIVEIRA, E., 2020).

\section{Satisfação e confiança em relação às fontes de informação}

Medidas eficazes de comunicação de riscos podem resultar no aumento da conscientização e na criação de confiança social nas autoridades. O fornecimento das informações corretas através de mídias adequadas pode desencadear um comportamento preventivo e melhorar os mecanismos de governança de riscos. Com foco na busca de informações relacionadas à pandemia, 50,7\% dos entrevistados acompanharam as notícias sobre o coronavírus frequentemente (pelo menos, uma vez ao dia) e 47,2\% sempre (várias vezes ao dia). Por essa razão, quando indagados sobre quão satisfeitos estão com as informações que recebem sobre a Covid-19, a maior parcela deles está satisfeita com as informações disponíveis $(73,2 \%)$ e entende que elas são fáceis de entender (77\%). No entanto, quando questionados sobre quais informações mais necessitam no momento, a maior parcela faz referência à evolução no desenvolvimento de tratamento e à vacina (30,7\%), ao progresso da doença (17,5\%), ao que fazer se estiver infectado (13,9\%), a como cuidar de uma pessoa que está no grupo de risco (13,1\%) e aos sintomas (12,4\%). As informações menos desejadas são histórias pessoais de outras pessoas sobre como elas lidam com a doença $(5,5 \%)$, detalhes sobre restrições de viagem (3,4\%), outros (2,5\%) e como pessoalmente é possível prevenir a propagação da doença (1,0\%).

Por outro lado, a escolha de uma mídia influencia o processo do indivíduo para entender a crise (UTZ; SCHULTZ; GLOCKA, 2013). Quando perguntados sobre qual é o nível de confiança das fontes de que recebem informações, os meios de comunicação que tiveram alta confiança foram apenas as fontes com dados disponibilizados pelos profissionais de saúde. Apresentaram baixo nível de confiança os seguintes meios de comunicação: folhetos e panfletos, informações dos familiares e amigos e informações oriundas das redes sociais (Facebook, Twitter e WhatsApp). Já as fontes de informações que apresentaram nível médio 
de confiança foram: sites ou portais de notícias, jornais. As informações dadas por celulares ou telefone sobre o novo coronavírus são as fontes de informação nas quais mais participantes $(45,1 \%)$ disseram que não confiam (Tabela 3).

Tabela 3 - Dados sobre confiança nas fontes de informação sobre a Covid-19

(continua)

\section{Característica $\quad$ Frequência (n) Porcentagem (\%)}

Qual é o grau de confiança que você possui nas seguintes fontes de informação sobre o novo coronavírus?

\begin{tabular}{|c|c|c|}
\hline \multicolumn{3}{|l|}{ [Televisão] } \\
\hline Alta & 442 & 34,2 \\
\hline Baixa & 171 & 13,2 \\
\hline Médio & 599 & 46,4 \\
\hline Não confio & 79 & 6,1 \\
\hline \multicolumn{3}{|l|}{ [Rádio] } \\
\hline Alta & 358 & 27,7 \\
\hline Baixo & 243 & 18,8 \\
\hline Médio & 621 & 48,1 \\
\hline Não confio & 69 & 5,3 \\
\hline \multicolumn{3}{|l|}{ [Jornais] } \\
\hline Alta & 525 & 40,7 \\
\hline Baixo & 139 & 10,8 \\
\hline Médio & 571 & 44,2 \\
\hline Não confio & 56 & 4,3 \\
\hline \multicolumn{3}{|c|}{ [Folhetos/Panfletos] } \\
\hline Alta & 96 & 7,4 \\
\hline Baixo & 456 & 35,3 \\
\hline Médio & 441 & 34,2 \\
\hline Não confio & 298 & 23,1 \\
\hline \multicolumn{3}{|l|}{ [Cartas] } \\
\hline Alta & 44 & 3,4 \\
\hline Baixo & 462 & 35,8 \\
\hline Médio & 309 & 23,9 \\
\hline Não confio & 476 & 36,9 \\
\hline \multicolumn{3}{|l|}{ [Revistas] } \\
\hline Alta & 238 & 18,4 \\
\hline Baixo & 302 & 23,4 \\
\hline Médio & 617 & 47,8 \\
\hline Não confio & 134 & 10,4 \\
\hline \multicolumn{3}{|c|}{ [Profissionais de saúde] } \\
\hline Alta & 982 & 76,1 \\
\hline Baixo & 21 & 1,6 \\
\hline Médio & 278 & 21,5 \\
\hline Não confio & 10 & 0,8 \\
\hline \multicolumn{3}{|c|}{ [Familiares e amigos] } \\
\hline Alta & 55 & 4,3 \\
\hline
\end{tabular}


(continuação)

\begin{tabular}{lcc}
\multicolumn{1}{c}{ Característica } & Frequência (n) & Porcentagem (\%) \\
\hline Baixo & 551 & 42,7 \\
Médio & 467 & 36,2 \\
Não confio & 218 & 16,9 \\
\hline [Sites ou portais de notícias] & & \\
Alta & 329 & 25,5 \\
Baixo & 227 & 17,6 \\
Médio & 679 & 52,6 \\
Não confio & 56 & 4,3 \\
[Mídias sociais (Facebook, Twitter, WhatsApp)] & \\
Alta & 22 & 1,7 \\
Baixo & 513 & 39,7 \\
Médio & 338 & 26,2 \\
Não confio & 418 & 32,4 \\
[E-mail] & & \\
Alta & 51 & 4,0 \\
Baixo & 471 & 36,5 \\
Médio & 398 & 30,8 \\
Não confio & 371 & 28,7 \\
[Chamada por telefone/celular] & & \\
Alta & 29 & 2,2 \\
Baixo & 411 & 31,8 \\
Médio & 269 & 20,8 \\
Não confio & 582 & 45,1 \\
\hline Fonte elaboça & \\
\hline
\end{tabular}

Fonte: elaboração dos autores.

Ao observar as respostas dos participantes, 97,6\% afirmam confiar muito ou até certo ponto nos profissionais de saúde para a obtenção das informações sobre a pandemia de Covid-19. Além da capacidade técnica dos profissionais, a população tem se deparado com os esforços de atuação dos médicos e enfermeiros. Até o mês de abril de 2020, por exemplo, o Ministério da Saúde informou que 500 mil profissionais de saúde haviam se cadastrado com interesse em atuar no combate ao novo coronavírus no país. Além disso, também houve a inscrição de estudantes de medicina que cursam os últimos anos de curso para o atendimento da população por telefone e online, e um pedido de adiantamento da conclusão de curso dos estudantes do último semestre em diversas faculdades do Brasil (OLIVEIRA, 2020).

Além do reconhecimento pelos esforços desses profissionais, as pessoas também compreendem os riscos a que eles estão diretamente submetidos, por conta do contato direto com pessoas contaminadas pelo coronavírus. Até meados de maio de 2020, mais de 30 mil profissionais de saúde já haviam sido contaminados pelo Covid-19 e, ainda, quase 200 mil estavam com suspeita de ter contraído a doença (VALENTE, 2020). Não obstante, no fim desse mesmo mês, 113 médicos e 143 enfermeiros já tinham entrado em óbito por conta do coronavírus, alcançando uma média de duas mortes diárias, desde a primeira confirmação. Entre as principais causas de contaminação dos profissionais estão a falta ou inadequação de equipamentos individuais de proteção para seu uso (NEVES, 2020).

No que se refere às outras fontes, cabe destacar que, embora o jornal impresso tenha perdido parte do público no decorrer dos anos, as empresas se adaptaram à chegada da internet, disponibilizando conteúdo por meio de assinatura digital e em sites de notícias. Essas alterações permitiram que a população tenha 
facilidade de acesso à informação, sendo essa considerada como uma das principais fontes com alto grau de confiança segundo os usuários. Anteriormente à situação pandêmica do país, em média 60\% da população considerava os jornais como fontes confiáveis (BRASIL, 2016). Com a necessidade de adquirir conhecimento contínuo perante o desenvolvimento da doença e as ações tomadas pelo governo, a confiança nos jornais, revelada pelos entrevistados em nossa pesquisa, chegou a 84,9\% (alta e média confiança).

Outro meio muito utilizado no mundo é a televisão, que alcança padrões distintos em diversos países, sobretudo ao considerar a sua cultura local. Nos Estados Unidos, por exemplo, 69\% das pessoas assistem à programação de TV ao mesmo tempo que utilizam o computador e 37\% usando o aparelho celular (MURDOCH; TUMA; VERNOCCHI, 2013; ERICSSON, 2017; SMITH; BOYLES, 2012). No Brasil, cerca de $89 \%$ das pessoas fazem uso da televisão diariamente para buscar notícias e informação. Cabe destacar que a utilização da internet em conjunto com a televisão também é uma prática adotada no país, onde $61 \%$ das pessoas fazem o uso paralelo das fontes.

A confiança expressa pelos usuários da televisão permanece alta: 80,6\% dos entrevistados afirmam ter alta ou média confiança no conteúdo apresentado pelos programas de TV. Por outro lado, ao observar o nível de confiança quanto às informações recebidas nas mídias sociais pela internet, $27,9 \%$ deles não concordam que elas devam ser utilizadas como principal base de comunicação de risco no enfrentamento da Covid-19. O grande problema enfrentado pelas redes sociais é que muitas notícias falsas são criadas e compartilhadas entre os usuários, as chamadas fake news (VOSOUGHI; ROY; ARAL, 2018). Segundo estudos da Organização de Pesquisa e Petições Online (Avaaz), de cada 10 brasileiros, nove já receberam notícias falsas sobre o coronavírus (AVAAZ, 2020). Logo, mesmo que as informações das autoridades tenham sido corretamente construídas, o excesso de informações torna alguns cidadãos incapazes de discernir mensagens erradas (MORENO; FUENTES-LARA; NAVARRO, 2020).

Entre as principais notícias falsas identificadas pelos usuários estão: o coronavírus foi criado por laboratório na China; a Covid-19 é igual à gripe comum com mortalidade igual ou menor; e tomar vitamina $\mathrm{C}$ impede a contaminação pelo coronavírus. Cabe destacar que essas mensagens são recebidas principalmente pelo WhatsApp e Facebook, além de serem transmitidas em conversas entre amigos e familiares (AVAAZ, 2020), o que também explica a falta de confiança de 16,9\% dos participantes nesse tipo de fonte). É importante ressaltar que o Ministério da Saúde possui um número de WhatsApp para que a população possa tirar dúvidas sobre informações recebidas da pandemia. Em cinco dias, estima-se que mais de 6.500 mensagens foram recebidas, sendo $85 \%$ destas de notícias falsas. Observa-se que, mesmo que muitas informações estejam sendo compartilhadas, isso não significa que elas sejam de qualidade (MARTINS, 2020).

Outro fator relevante para a pesquisa aqui revelada se refere às recomendações e restrições adotadas pelos estados e municípios do Brasil. De maneira geral e em alguma medida, as instruções da OMS em relação às medidas de distanciamento social, limpeza frequente das mãos e utilização de máscara foram adotadas em todo o país. Mas, ao observar as medidas restritivas para diminuir a contaminação nos estados, observa-se uma contrariedade nas diversas regiões. O funcionamento do comércio é um exemplo disso, o que levou diversos centros urbanos a liberarem a sua reabertura em períodos críticos de evolução da doença. A utilização de parques e outros espaços abertos também é ponto de dúvida em diferentes estados. A suspensão das aulas e de eventos foram as únicas medidas restritas em todos os municípios até o fim de 2020 (FERENTZ; FONSECA; GARCIAS, 2020). Observa-se que as alterações constantes realizadas pelos governantes, quanto às restrições, também são fatores complicadores para o entendimento da população sobre os seus deveres perante a prevenção da Covid-19.

Por fim, destaca-se que a grande limitação do estudo aqui revelado é referente à abordagem metodológica adotada com foco em análises quantitativas por meio de questionários aplicados aos participantes. Sabe- 
se que a percepção de risco varia de pessoa para pessoa e a aplicação de um questionário online possui restrições nesse sentido. Entretanto, a referida pesquisa foi desenvolvida durante o período de pandemia, quando o isolamento e distanciamento social são necessários. Assim, para melhorar o entendimento sobre a percepção de risco e sua relação com a comunicação, novos estudos com abordagem mista (qualitativo e quantitativo) são necessários, após a liberação das restrições impostas perante os riscos de disseminação da Covid-19.

\section{CONCLUSÃO}

A pesquisa aqui exposta atendeu ao objetivo proposto, possibilitando uma análise das fontes de comunicação utilizadas para o enfrentamento da Covid-19 no Brasil. Foi possível observar que os participantes confiam nas informações concedidas diretamente pelos profissionais de saúde, assim como de sites e páginas oficiais, jornais e televisão. Por outro lado, embora as mídias sociais sejam cada vez mais usadas pelos brasileiros, ao se tratar de assuntos sérios, como os da pandemia provocada pelo coronavírus, as pessoas não têm confiança nas informações compartilhadas. Esse fato se dá pelo número de notícias falsas que são recebidas diariamente.

Percebe-se que existe uma fragilidade quanto às medidas tomadas pelos estados e municípios para minimizar a disseminação da doença. Elas não são tomadas em conjunto, de tal forma que cada região adota suas próprias diretrizes. Como resultado, embora a população esteja recebendo a informação por meio de diversas fontes, a flexibilização das medidas de isolamento social em diferentes cidades do Brasil tem desencadeado o aumento da contaminação em todo o país. Mais do que isso, é preciso entender se as informações divulgadas sobre a Covid-19 em diferentes tipos de mídia são transformadas em conhecimento e, por conseguinte, em medidas de prevenção e preparação. Sem isso, é pouco provável que as medidas sejam exitosas.

Desse modo, é necessária a adoção de novas estratégias locais, antes que os sistemas brasileiros de saúde e econômico entrem em colapso. Em um cenário de cada vez mais incertezas, no qual as crises farão parte do novo normal e pandemias surgirão, a preparação é fundamental para a administração pública e, sobretudo, vai além de respostas eficientes e únicas. Todos os atores sociais de um sistema urbano só podem estar preparados se investirem em relações reflexivas, bem como em gestão ágil e robusta de sistemas de comunicação antes da ocorrência de qualquer evento extremo.

\section{REFERÊNCIAS}

AUSTIN, Lucinda; LIU, Brooke Fisher; JIN, Yan. How audiences seek out crisis information: Exploring the social-mediated crisis communication model. Journal of Applied Communication Research, Londres, v. 40, n. 2, p. 188-207, 2012. DOI: https://doi.org/10.1080/00909882.2012.654498. Disponível em: https://www. tandfonline.com/doi/full/10.1080/00909882.2012.654498. Acesso em: 8 jun. 2021.

BARRY, John. M. Pandemics: avoiding the mistakes of 1918. Nature, Londres, v. 459, n. 7245, p.459-325, 2009. DOI: https://doi.org/10.1038/459324a. Disponível em: https://www.nature.com/articles/459324a. Acesso em: 8 jun. 2021.

BEAN, Hamilton; SUTTON, Jeannette; LIU, Brooke F.; MADDEN, Stephanie; WOOD, Michele M. et al. The study of mobile public warning messages: a research review and agenda. Review of Communication, Londres, v. 15, n. 1, p. 60-80, 2015. DOI: https://doi.org/10.1080/15358593.2015.1014402. Disponível em: https://www.tandfonline.com/doi/full/10.1080/15358593.2015.1014402. Acesso em: 4 jun. 2021.

BRASIL. Ministério da Saúde. Painel Coronavírus. 2020. Disponível em: https://covid.saude.gov.brl. Acesso em: 1 jun. 2020.

BRASIL. Secretaria de Comunicação Social. Pesquisa brasileira de mídia 2016: hábitos de consumo de mídia pela população brasileira. Brasília, DF: Secom, 2016. 
CHEN, Nanshan; ZHOU, Min; DONG, Xuan; QU, Jieming et al. Epidemiological and clinical characteristics of 99 cases of 2019 novel coronavirus pneumonia in Wuhan, China: a descriptive study. The Lancet, Londres, v. 395, n. 10223, p. 507-513, 2020. DOI: https://doi.org/10.1016/S0140-6736(20)30211-7. Disponível em: https://www.thelancet.com/journals/lancet/article/PIIS0140-6736(20)30211-7/fulltext. Acesso em: 4 jun. 2021.

DZIALEK, Jaroslaw; BIERNACKI, Wojciech; KONIECZNY, Roman; FIEDEŃ, Lukazs. et al. Online flood risk communication. In: DZIALEK, Jaroslaw; BIERNACKI, Wojciech; KONIECZNY, Roman; FIEDEŃ, Lukazs. et al. Understanding flood preparedness flood memories, social vulnerability and risk communication in Southern Poland. Nova lorque: SpringerBriefs in Geography, 2019. p. 91-113.

ERICSSON. TV and Media 2017: A consumer-driven future of media. Sweden: Ericsson consumer and Industry Insight Report, 2017. E-book. Disponível em: https://www.ericsson.com/49e9a2/assets/local/ reports-papers/consumerlab/reports/2017/tv-media-2017-consumer-and-industry-insight-report.pdf. Acesso em: 8 jun. 2020.

FELDMAN, David; CONTRERAS, Santina; KARLIN, Beth; BASOLO, Victoria et al. Communicating flood risk: looking back and forward at traditional and social media outlets. International Journal of Disaster Risk Reduction, Londres, v. 15, p. 43-45, 2016. DOI: https://doi.org/10.1016/j.ijdrr.2015.12.004. Disponível em: https://www.sciencedirect.com/science/article/abs/pii/S2212420915300765?via\%3Dihub. Acesso em: 4 jun. 2021.

FERENTZ, Larissa Maria da Silva; FONSECA, Murilo Noli da; GARCIAS, Carlos Mello. Covid-19 response measures in Brazilian states: legislative and journalistic approach. Qualitas, Campina Grande, v. 21, n. 3, set.dez. 2020. DOI: http://dx.doi.org/10.18391/req.v21i3.5653. Disponível em: http://revista.uepb.edu.br/index. php/qualitas/article/view/5653. Acesso em: 8 jun. 2021.

FINSET, Arnstein; BOSWORTH, Hayden; BUTOW, Phyllis; GULBRANDSEN, Pal et al. Effective health communication - a key factor in fighting the Covid-19 pandemic. Patient Education and Counseling, Londres, v. 103, n. 5, p. 873-876, 2020. DOI: https://doi.org/10.1016/j.pec.2020.03.027. Disponível em: https://www.sciencedirect.com/science/article/abs/pii/S0738399120301853?via\%3Dihub. Acesso em: 4 jun. 2021.

FRENKEL, Sheera; ALBA, Davey; ZHONG, Raymond. Surge of virus misinformation stumps Facebook and Twitter. The New York Times, 8 mar. 2020. Technology. Disponível em: https://www.nytimes. com/2020/03/08/technology/coronavirus-misinformation-socialmedia.html. Acesso em: 1 jun. 2020.

FRISBY, Brandi; VEIL, Shari R.; SELLNOW, Timothy L. Instructional messages during health-related crises: Essential content for self-protection. Health communication, Londres, v. 29, n. 4, p. 347-354, 2014. DOI: https://doi.org/10.1080/10410236.2012.755604. Disponível em: https://www.tandfonline.com/doi/abs/10.10 80/10410236.2012.755604. Acesso em: 22 maio 2021.

GEVERS, Alex. What consumers in Europe do online during the lockdown. Comscore, [s. I.], 8 abr. 2020. Blog. Disponível em: https://www.comscore.com/por/lnsights/Blog/What-consumers-in-Europe-do-online-duringthe-lockdown. Acesso em: 11 jun. 2020.

GLIK, Deborah C. Risk communication for public health emergencies. Annual Reviews of Public Health, Palo Alto, v. 28, p. 33-54, 2007. DOI: https://doi.org/10.1146/annurev.publhealth.28.021406.144123. Disponível em: https://www.annualreviews.org/doi/10.1146/annurev.publhealth.28.021406.144123. Acesso em: 4 jun. 2021.

HEATH, Robert L.; O'HAIR, Dan (ed.). Handbook of risk and crisis communication. New York: Routledge, 2009.

HUANG, Chaolin; WANG, Yeming; LI, Xiangwang; REN, Lili et al. Clinical features of patients infected with 2019 novel coronavirus in Wuhan, China. The Lancet, Londres, v. 395, n. 10223, p. 497-506, 2020. DOI: https://doi.org/10.1016/S0140-6736(20)30183-5. Disponível em: https://www.thelancet.com/journals/ lancet/article/PIIS0140-6736(20)30183-5/fulltext. Acesso em: 4 jun. 2021.

INSTITUTO BRASILEIRO DE GEOGRAFIA E ESTATÍSTICA (IBGE). PNAD Contínua TIC 2017: Internet chega a três em cada quatro domicílios do país. Agência IBGE Notícias, Rio de Janeiro, 20 dez. 2018. Estatísticas Sociais. Disponível em: https://agenciadenoticias.ibge.gov.br/agencia-sala-de-imprensa/2013-agencia-denoticias/releases/23445-pnad-continua-tic-2017-internet-chega-a-tres-em-cada-quatro-domicilios-do-pais. Acesso em: 11 jun. 2020 
KEMP, Simon. Digital around the world in April 2020. We Are Social, [s. I.], 23 abr. 2020. Special Reports. Disponível em: https://wearesocial.com/blog/2020/04/digital-around-the-world-in-april-2020. Acesso em: 11 jun. 2020.

LAMOND, Jessica; ADEKOLA, Olalekan; ADELEKAN, Ibidun; EZE, Bassey et al. Information for adaptation and response to flooding, multi-stakeholder perspectives in Nigeria. Climate, Londres, v. 7, n. 4, p. 1-18, 2019. DOI: https://doi.org/10.3390/cli7040046. Disponível em: https://www.mdpi.com/2225-1154/7/4/46. Acesso em: 4 jun. 2021.

LU, Roujian; ZHAO, Xiang; LI, Juan; NIU, Peihua et al. Genomic characterisation and epidemiology of 2019 novel coronavirus: implications for virus origins and receptor binding. The Lancet, Londres, v. 3395, n. 10224, p. 565-574, 2020. DOI: https://doi.org/10.1016/S0140-6736(20)30251-8. Disponível em: https://www. thelancet.com/journals/lancet/article/PIIS0140-6736(20)30251-8/fulltext. Acesso em: 4 jun. 2021.

MARTINS, Helena. Pandemia expõe importância das tecnologias e universalização do acesso à rede, mas também riscos de ampliação de controle. Carta Capital, São Paulo, 17 mar. 2020. Intervozes. Disponível em: https://www.cartacapital.com.br/blogs/intervozes/coronavirus-falta-de-acesso-a-internet-amplia-fosso-dedesigualdades/. Acesso em: 27 jan. 2021.

MASIP, Pere; ARAN-RAMSPOTT, Sue; RUIZ-CABALLERO, Carlos; SUAU, Jaume et al. Consumo informativo y cobertura mediática durante el confinamiento por el Covid-19: sobre información, sesgo ideológico y sensacionalismo. Profesional de la Información, Barcelona, v. 29, n. 3, p. 290-312, 2020. DOI: https://doi. org/10.3145/epi.2020.may.12. Disponível em: https://revista.profesionaldelainformacion.com/index.php/ EPl/article/view/epi.2020.may.12. Acesso em: 4 jun. 2021.

MILETI, Dennis S.; SORENSEN, John H. Communication of emergency public warnings: a social science perspective and state-of-the-art assessment. Washington (DC): Colorado State University, 1990. DOI: https:// doi.org/10.2172/6137387. Disponível em: https://www.osti.gov/biblio/6137387-communication-emergencypublic-warnings-social-science-perspective-state-art-assessment. Acesso em: 4 jun. 2021.

MORENO, Angeles; FUENTES-LARA, Cristina; NAVARRO, Cristina. Covid-19 communication management in Spain: Exploring the effect of information-seeking behavior and message reception in public's evaluation. Profesional de la Información, Barcelona, v. 29, n. 4, p. 290402, 2020. DOI: https://doi.org/10.3145/ epi.2020.jul.02. Disponível em: https://revista.profesionaldelainformacion.com/index.php/EPl/article/view/ epi.2020.jul.02. Acesso em: 02 jul. 2020.

MORGAN, J. P. Media consumption in the age of Covid-19: against the backdrop of the Coronavirus pandemic, increased media consumption is helping to fill the time. 2020. Disponível em: https://www. jpmorgan.com/global/research/media-consumption. Acesso em: 11 jun. 2020.

MORI, Letícia. Coronavírus: tudo o que você precisa saber sobre o uso ou não de máscaras. BBC News Brasil, São Paulo, 26 mar. 2020. Disponível em: https://www.bbc.com/portuguese/brasil-52030633. Acesso em: 11 jun. 2020.

MURDOCH, Robin; TUMA, Youssef; VERNOCCHI, Marco. The eyes have it: guess who controls the future of TV. Outlook the jounal of high-performance business, n.1, p. 1-8, 2013. Disponível em: http://www. accenture.com/us-en/outlook/Pages/outlook-journal-2013-eyes-have-it-who-controls-future-of-televisionmedia.aspx. Acesso em: 22 maio 2021.

NEUWIRTH, Kurt; DUNWOODY, Sharon; GRIFFIN, Robert J. Protection motivation and risk communication. Risk Analysis, McLean, v. 20, n. 5, p. 721-734, 2000. DOI: https://doi.org/10.1111/0272-4332.205065. Disponível em: https://onlinelibrary.wiley.com/doi/abs/10.1111/0272-4332.205065. Acesso em: 4 jun. 2021.

NEVES, Úrsula. Covid-19, Brasil ultrapassa a marca de cem médicos mortos por conta do vírus. Portal Pebmed, [s. I.], 27 maio 2020. Saúde Pública. Disponível em: https://pebmed.com.br/covid-19-brasilultrapassa-a-marca-de-cem-medicos-mortos-por-conta-do-virus/. Acesso em: 27 maio 2020.

OLIVEIRA, Elida. Uso de máscaras diminui vírus no ambiente e pode frear $2^{\mathrm{a}}$ onda de contaminação por coronavírus no Brasil, diz médica. G1, Rio de Janeiro, 2 abr. 2020. Coronavirus. Disponível em: https:// g1.globo.com/bemestar/coronavirus/noticia/2020/04/02/uso-de-mascaras-diminui-virus-no-ambientee-pode-frear-2a-onda-de-contaminacao-por-coronavirus-no-brasil-diz-medica.ghtml. Acesso em: 11 jun. 2020. 
OLIVEIRA, Tinna. 500 mil profissionais dispostos a atuarem no combate ao coronavírus. Agência Saúde, Brasília, DF, 28 abr. 2020. Disponível em: https://antigo.saude.gov.br/noticias/agencia-saude/46805-500mil-profissionais-dispostos-a-atuarem-no-combate-ao-coronavirus. Acesso em: 8 jun. 2020.

ORGANIZAÇÃO DE PESQUISA E PETIÇÕES ONLINE (AVAAZ). O Brasil está sofrendo uma infodemia de Covid-19. Avaaz, [s. I.], 4 maio 2020. Disponível em: https://secure.avaaz.org/campaign/po/brasil infodemia coronavirus/. Acesso em: 26 maio 2020.

PARK, Sejin; BOATWRIGHT, Brandon; JOHNSON-AVERY, Elizabeth. Information channel preference in health crisis: Exploring the roles of perceived risk, preparedness, knowledge, and intent to follow directives. Public Relations Review, Londres, v. 45, n. 5, p. 101794, 2019. DOI: https://doi.org/10.1016/j.pubrev.2019.05.015. Disponível em: https://www.sciencedirect.com/science/article/abs/pii/S0363811118306192. Acesso em: 4 jun. 2021

PING, Neoh Siew; WEHN, Uta; ZEVENBERGEN, Chris; ZAAG, Pieter van der. Towards two-way flood risk communication: current practice in a community in the UK, Journal of Water and Climate Change, Londres, v. 7, n. 4, p. 651-664, 2016. DOI: https://doi.org/10.2166/wcc.2016.015. Disponível em: https://iwaponline. com/jwcc/article/7/4/651/1618/Towards-two-way-flood-risk-communication-current. Acesso em: 4 jun. 2021.

PLIGT, Joop van der. Risk perception and self-protective behavior. European Psychologist, Göttingen, v.1, n. 1, p. 34-43, 1996. DOI: https://doi.org/10.1027/1016-9040.1.1.34. Disponível em: https://econtent.hogrefe. com/doi/10.1027/1016-9040.1.1.34. Acesso em: 4 jun. 2021.

PROULX, Mike; SHEPATIN, Stacey. Social TV: how marketers can reach and engage audiences by connecting television to the web, social media, and mobile. Hoboken: Wiley Publishing, 2012.

RASMUSSEN, Sonja A.; GOODMAN, Richard A. The CDC Field Epidemiology Manual. Oxônia: Oxford University Press, 2018.

REINTJES, Ralf; DAS, Enny; KLEMM, Celine; RICHARDUS, Jan Hendrik et al. Pandemic public health paradox: time series analysis of the 2009/10 influenza $A / H(1) N(1)$ epidemiology, media attention, risk perception and public reactions in 5 European countries. PLoS One, San Francisco, v. 11, n. 3, p. e0151258, 2016. DOI: https://doi.org/10.1371/journal.pone.0151258. Disponível em: https://journals.plos.org/plosone/ article?id=10.1371/journal.pone.0151258. Acesso em: 4 jun. 2021.

REYNOLDS, Barbara; SEEGER, Matthew. Crisis and emergency risk communication as an integrative model. Journal of Health Communication, Cresskill, v. 10, n. 1, p. 43-55, 2005. DOI: https://doi.org/10.1080/10810730590904571. Disponível em https://www.tandfonline.com/doi/ abs/10.1080/10810730590904571. Acesso em: 4 jun. 2021.

SCHMID, Phillip; BETSCH, Cornelia. Effective strategies for rebutting science denialism in public discussions. Nature Human Behaviour, Londres, v. 3, p. 931-939, 2019. Disponível em: https://www.nature.com/articles/ s41562-019-0632-4. Acesso em: 1 jun. 2020.

SMITH, Aaron; BOYLES, Jan Lauren. The rise of the "connected viewer": half of cell owners use their phones for distraction or engagement while watching television. Pew Research Center, Washington, DC, 17 jul. 2012. Research Topics. Disponível em: https://www.pewresearch.org/internet/2012/07/17/the-rise-of-theconnected-viewer-2l. Acesso em: 11 jun. 2020.

THE LANCET. Covid-19: fighting panic with information. The Lancet, Londres, v. 395, n. 10224, p. 537, 2020. DOI: https://doi.org/10.1016/S0140-6736(20)30379-2. Disponível em: https://www.thelancet.com/journals/ lancet/article/PIIS0140-6736(20)30379-2/fulltext. Acesso em: 4 jun. 2021.

UTZ, Sonja; SCHULTZ, Friederike; GLOCKA, Sandra. Crisis communication online: How medium, crisis type and emotions affected public reactions in the Fukushima Daiichi nuclear disaster. Public Relations Review, Londres, v. 39, n. 1, p. 40-46, 2013. DOI: https://doi.org/10.1016/j.pubrev.2012.09.010. Disponível em: https://www.sciencedirect.com/science/article/abs/pii/S0363811112001816?via\%3Dihub. Acesso em: 11 jun. 2020.

VALENTE, Jonas. No Brasil, 31.790 profissionais de saúde contraíram covid-19. Agência Brasil, Brasília, DF, 14 maio 2020. Saúde. Disponível em: https://agenciabrasil.ebc.com.br/saude/noticia/2020-05/no-brasil31790-profissionais-de-saude-contrairam-covid-19. Acesso em: 26 maio 2020. 
VOSOUGHI, Soroush; ROY, Deb; ARAL, Sinan. The spread of true and false news online. Science, Pensilvânia, v. 359, n. 6380, p. 1146-1151, 2018. DOI: https://doi.org/10.1126/science.aap9559. Disponível em: https://science.sciencemag.org/content/359/6380/1146. Acesso em: 4 jun. 2021.

WALTER, D.; BOHMER, M.; REITER, S.; KRAUSE, G. et al. Risk perception and information seeking behaviour during the 2009/10 influenza A(H1N1)pdm09 pandemic in Germany. Euro Surveillance, SaintMaurice, v. 17, n. 13, p. 20131, 2012. Disponível em: https://pubmed.ncbi.nlm.nih.gov/22490383/. Acesso em: 4 jun. 2021.

WHO REGIONAL OFFICE FOR EUROPE. Covid-19 Snapshot Monitoring (COSMO): monitoring knowledge, risk perceptions, preventive behaviours, and public trust in the current coronavirus outbreak. [S. I.]: Psych Archives, 2020. DOI: http://dx.doi.org/10.23668/psycharchives.2782. Disponível em: https://www. psycharchives.org/handle/20.500.12034/2392. Acesso em: 4 jun. 2021.

WORLD HEALTH ORGANIZATION (WHO). Novel coronavirus (2019-nCoV). 2019. Disponível em: https:// www.who.int/emergencies/diseases/novel-coronavirus-2019/situation-reports. Acesso em: 25 mar. 2020.

ZHU, Na; ZHANG, Dingyu; WANG, Weiling; LI, Xiangwang et al. A novel coronavirus from patients with pneumonia in China, 2019. The New England Journal of Medicine, Waltham, v. 382, n. 8, p. 727-733, 2020. DOI: https://doi.org/10.1056/NEJMoa2001017. Disponível em: https://www.nejm.org/doi/10.1056/ NEJMoa2001017. Acesso em: 4 jun. 2021. 